\title{
Inclusion trapping during disequilibrium pegmatite crystallization: lessons from tourmaline-quartz intergrowths
}

MONA-LiZA C. SiRBESCU1*, NiEls HulsBOSCH2

1Central Michigan Univ., Mount Pleasant, MI, USA

(*correspondence: sirbe1mc@cmich.edu)

${ }_{2} \mathrm{KU}$ Leuven Univ., Leuven, Belgium

Tourmaline-quartz intergrowths (QTI's) occur in rapidly cooled wall zones of granitic pegmatites (e.g., Black Hills, South Dakota; Oxford Co., Maine; San Diego, California, etc.). This poorly studied skeletal, disequilibrium texture may hold clues about the magmatic evolution and potential development of diffusion-controlled boundary layers and localized fluid saturation at early magmatic stage of crystallization. Unlike graphic quartz-feldspar, tourmaline hosts well preserved crystallized melt inclusion (MI's) and fluid inclusions (FI's). Tourmaline tapered habit indicates direction of growth, whereas its color zones allow sequence "stratigraphy" interpretations of inclusion assemblages. Comb-textured, radiating schorl-dravite to foitite tourmaline crystals $(<0.5 \mathrm{~m}$ long) nucleated in the hanging wall of Emmons pegmatite, Maine and developed remarkable QTI's comprised of optically coherent central tourmaline prisms and skeletal "branches" intergrown with coarse, anhedral quartz.

Crystallized MI's were mapped through high-resolution, confocal Raman spectroscopy, using 3D imagining and multivariate spectral fitting. We integrated full-spectrum mixture analysis and database matching to separate the daughter-mineral and host-tourmaline spectra. Primary crystallized MI's in the rims of central tourmaline contain quartz ( $\sim 5 \%$ by area); peraluminous phases muscovite $(\sim 30 \%)$, pyrophyllite $(0-5 \%)$, and garnet $(<2 \%)$; and aqueouscarbonic fluid (15-25\%). Carbonates and phosphates (5-10\%) demonstrate progressive flux-component enrichment at the transition between subhedral to skeletal growth. Moreover, the fluid content in the MI's and the abundance of primary, aqueous-carbonic FI's increase in the skeletal zone.

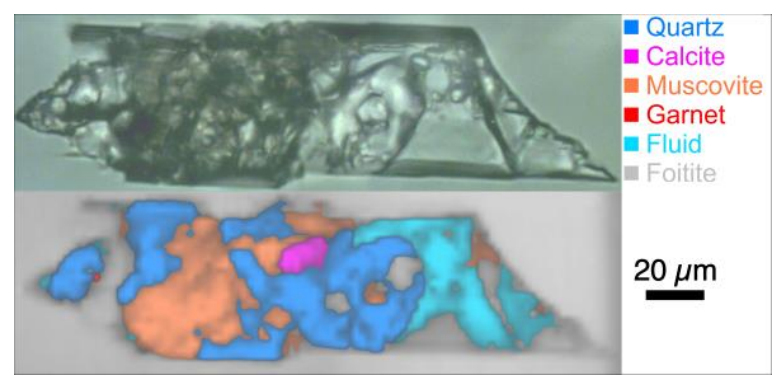

